\title{
fyn tyrosine kinase is involved in keratinocyte differentiation control
}

\author{
Enzo Calautti, ${ }^{1,3}$ Caterina Missero, ${ }^{1}$ Paul L. Stein, ${ }^{4}$ Robert M. Ezzell, ${ }^{2}$ and G. Paolo Dotto ${ }^{1,5}$ \\ ${ }^{1}$ Cutaneous Biology Research Center, ${ }^{2}$ Surgery Research Unit, Massachusetts General Hospital and Harvard Medical School, \\ Charlestown, Massachusetts 02129 USA, ${ }^{3}$ Department of Genetics, Biology and Medical Chemistry, University of Torino, \\ Italy and ${ }^{4}$ Wistar Institute, Philadelphia, Pennsylvania 19104 USA
}

\begin{abstract}
Induction of tyrosine phosphorylation is an early and specific event which is required for mouse keratinocyte differentiation to occur, in response to both calcium and TPA (12-0-tetradecanoylphorbol-13-acetate). We report here that there is an increase of tyrosine kinase activity immunoprecipitable with anti-phosphotyrosine antibodies specifically in response to calcium-and a number of other divalent cations-within 2 min of exposure. Such an activity does not correspond to any of the known tyrosine kinases that were tested. A second tyrosine kinase activity is induced in response to both calcium and TPA, and has been identified as fyn, a nonreceptor tyrosine kinase of the $s r c$ family. fyn activation is induced in keratinocytes within $6 \mathrm{hr}$ of calcium exposure, but already within 2 min of TPA treatment. Cortactin, a p80-85 substrate of src- and fyn-related kinases that localizes with actin at cell adhesion sites, is increasingly tyrosine phosphorylated in calcium- and TPA-induced differentiation, with a time course which parallels that of fyn activation.

Keratinocytes with a specific disruption of the fyn, but not yes kinase gene show no induction of phosphorylation of p80-85 proteins, and are significantly altered in their differentiation response both in vitro and in vivo. Thus, at least two tyrosine kinase activities are induced in keratinocyte differentiation, one of which has been identified as fyn and shown to be specifically involved in this process.
\end{abstract}

[Key Words: fyn tyrosine kinase; calcium; TPA; keratinocyte differentiation; cortactin]

Received January 26, 1995; revised version accepted August 4, 1995.

Control of terminal differentiation in normal epithelial cells is still poorly understood. Mouse primary keratinocytes provide an ideal system to elucidate this process. Addition of calcium to cultured keratinocytes triggers a terminal differentiation program which closely resembles that in the skin (Hennings et al. 1980; Hennings and Holbrook 1983). A gradient of increasing calcium concentrations in the upper epidermal layers (Menon et al. 1985) suggests that this ion could be involved in control of keratinocyte differentiation even in vivo. Calcium can exert its effects in two distinct fashions. It can act at the cell surface, favoring processes such as cell-cell and cellsubstrate interactions (Luna and Hitt 1992), and possibly triggering a transmembrane calcium-receptor mechanism (Filvaroff et al. 1994). It can also induce intracellular signaling pathways, through direct modifications of intracellular ion concentrations (Hennings et al. 1983; Reiss et al. 1991; and references therein) and phospholipase $\mathrm{C}$ (PLC) and protein kinase $\mathrm{C}$ (PKC) activation (Moscat et al. 1989; Lee and Yuspa 1991; and references therein).

Like calcium, the skin tumor promoter TPA (12-Otetradecanoylphorbol-13-acetate) can elicit some important aspects of keratinocyte differentiation, such as

\footnotetext{
${ }^{5}$ Corresponding author.
}

growth arrest, loricrin and filaggrin production, epidermal transglutaminase activation, and cornification (Dlugosz and Yuspa 1993; and references therein). However, certain other aspects of keratinocyte differentiation triggered by calcium, such as desmosome formation, keratin bundle reorganization and keratin 1 and 10 expression fail to be induced by TPA (Dlugosz and Yuspa 1993). These biological effects suggest that TPA activates signaling pathways partially overlapping with those triggered by calcium. This possibility is further supported by the fact that keratinocyte variants selected for resistance to calcium-induced differentiation are often also resistant to the effects of TPA (Yuspa et al. 1983; Dotto et al. 1986).

As has been shown in other differentiation and developmentally regulated systems (Pazin and Williams 1992), induction of tyrosine phosphorylation is an early and specific event which is required for keratinocyte differentiation, in response to both calcium and TPA (Filvaroff et al. 1990). In particular, tyrosine phosphorylation of a single protein of $\sim 60 \mathrm{kD}$ is induced in keratinocytes specifically in response to calcium, as early as $5^{\prime}$ after exposure, while tyrosine phosphorylation of a second protein of $\sim 80-85 \mathrm{kD}$ is induced by both calcium and TPA. The first protein has been identified as "p62" (Filvaroff et al. 1992), a tyrosine phosphorylated protein 
which associates with ras-GAP (Ellis et al. 1990) and which belongs to a novel family of RNA binding proteins (G. Wong et al. 1992).

Nothing is known about the tyrosine kinases activated in mouse keratinocyte differentiation. We report here that at least two distinct tyrosine kinase activities are involved. One activity can be immunoprecipitated with anti-phosphotyrosine antibodies, and is induced specifically in response to calcium-and a number of other divalent cations-within 2 min of exposure. The identity of this activity remains to be established. The other activity is induced in response to both calcium and TPA, and has been identified as fyn, a nonreceptor tyrosine kinase of the src family. fyn activation is observed a few hours after calcium-induced differentiation, but already within 2 min of TPA treatment.

To date, nine tyrosine kinases of the src family have been identified, which share similar structural and biochemical properties, but differ in some of the upstream and downstream signaling molecules with which they interact (Brickell 1992; Bolen 1993). Six of these kinases, $f g r, l c k, b l k, h c k, l y n, y r k$, are expressed with a high degree of tissue specificity, consistent with their involvement in specialized cellular functions. Three kinases, src, yes and fyn, are widely expressed, and appear to have a general role in cell growth and differentiation, as well as more specific cell-type related functions. Functional compensation between these three kinases has been revealed by gene knockout experiments in mice, with homozygous deletions of a single kinase gene causing limited effects, at sites which do not necessarily correlate with kinase expression levels (Soriano et al. 1991; Appleby et al. 1992; Stein et al. 1992; 1994). However, a finer analysis of the mutant mice can still provide important insights into the role of a given kinase in specific cellular functions.

Disruption of the fyn gene was previously found to cause altered T-cell receptor signaling in thymocytes, with mature $T$ cells being only minimally affected (Appleby et al. 1992; Stein et al. 1992). Hippocampal function in fyn-negative mice is also abnormal (Grant et al. 1992), while other parts of the nervous system, where fyn is also usually expressed, are essentially normal. Here, we show that, in parallel with our biochemical findings, fyn-deficient keratinocytes are significantly altered in their differentiation response both in vitro and in vivo. In contrast to these cells, keratinocytes of yesmutant mice exhibit an essentially normal differentiation response.

Thus, two distinct tyrosine kinases are induced in keratinocyte differentiation, one of which has been identified as fyn and shown to be specifically involved in this process.

\section{Results}

A tyrosine kinase activity immunoprecipitable with anti-phosphotyrosine antibodies is induced at very early times of calcium-induced differentiation

Activation of most tyrosine kinases is associated with their autophosphorylation. Furthermore these enzymes are often found in association with other tyrosine phosphorylated proteins, including their substrates. We tested whether the tyrosine kinases activated at early times of keratinocyte differentiation could be recognized and immunoprecipitated by anti-phosphotyrosine antibodies. Extracts were prepared from mouse primary keratinocytes under growing conditions and at various times of calcium- or TPA-induced differentiation. Extracts were normalized for protein content and immunoprecipitated with anti-phosphotyrosine monoclonal antibodies PY20 (Glenney et al. 1988). The immunoprecipitates were tested by in vitro kinase assays with enolase as exogenous substrate. As shown in Figure 1, there was a significant increase in tyrosine kinase activity in antiphosphotyrosine immunoprecipitates from keratinocytes exposed to high calcium medium, relative to those from keratinocytes kept under growing conditions. Increased activity was detectable as early as $2 \mathrm{~min}$ after calcium addition, and remained at even higher levels for up to $24 \mathrm{hr}$ (Fig. 1A,B). Tyrosine phosphorylation of the enolase substrate was confirmed by direct phosphoamino acid analysis (Fig. 1C). These results were confirmed by in vitro kinase assays with poly $(\mathrm{Glu} / \mathrm{Tyr})$ as an exogenous substrate (data not shown).

In contrast to calcium, there was no induction of tyrosine kinase activity in anti-phosphotyrosine immunoprecipitates from keratinocytes at early times of TPA exposure (Fig. 1D). In parallel with our previous findings on p62 tyrosine phosphorylation (Filvaroff et al. 1994), induction of anti-phosphotyrosine-immunoprecipitable kinase activity was also induced by exposure to magnesium and, to an even greater extent, cobalt and nickel ions, whereas no induction was observed after treatment with the calcium ionophore A23187 (Fig. 1D).

Thus, a tyrosine kinase activity which could be immunoprecipitated with anti-phosphotyrosine antibodies was specifically induced at very early times of calciumbut not TPA - induced differentiation. A similar induction was also observed after exposure of keratinocytes to a number of divalent cations, but not to a calcium ionophore.

\section{The fyn tyrosine kinase is induced at later times of calcium-induced differentiation and at very early times of TPA treatment}

The calcium-induced kinase activity could correspond to a known tyrosine kinase. To test this possibility, in vitro kinase assays similar to the ones described above were performed, after immunoprecipitation with antibodies specific for a number of known tyrosine kinases (Table 1). None of the tested kinases was found to be activated within a few minutes of calcium-induced differentiation (data not shown). However, a significant induction of tyrosine kinase activity was found in immunoprecipitates with cst-1 antiserum starting after $1 \mathrm{hr}$ of calcium exposure and remaining elevated up to $24 \mathrm{hr}$ (Fig. 2). The cst-1 antiserum recognizes an epitope common to three kinases of the src family, src, yes, and fyn (Courtneidge 

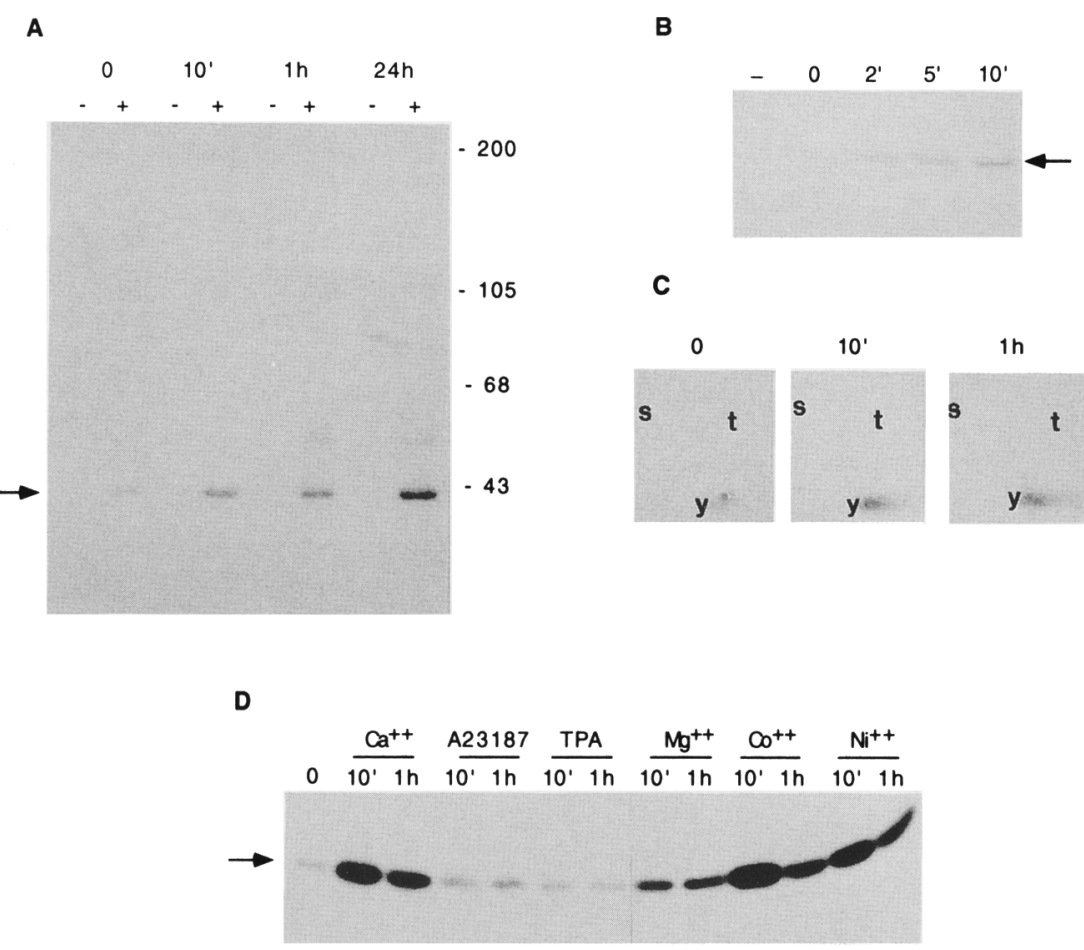

Figure 1. Anti-phosphotyrosine immunoprecipitable tyrosine kinase activity in iontreated mouse primary keratinocytes. $(A, B)$ Primary mouse keratinocytes were exposed to high calcium concentrations $(2 \mathrm{~mm})$ for the indicated amounts of time. Extracts were immunoprecipitated with anti-phosphotyrosine mAbs Py $20(+)$ and control antibodies $(-)$ and tested by in vitro kinase assays in the presence of enolase as exogenous substrate. Phosphorylation products were separated on $10 \%$ SDS-PAGE and detected by autoradiography. Positions of molecular size markers and of the enolase substrate (arrow) are indicated. Similar results were obtained in ten independent experiments. $(C)$ Direct phosphoamino acid anal$y$ sis of the eluted enolase substrate shown in panel A. Internal standard positions for phospho-serine $(s)$, phospho-threonine $(t)$ and phospho-tyrosine $(\mathrm{y})$ are indicated. $(D)$ Keratinocytes were exposed to calcium (2 $\mathrm{mM}), \mathrm{A} 23187(2 \mu \mathrm{M})$, TPA (100 $\mathrm{ng} / \mathrm{ml})$, magnesium (5 $\mathrm{mm})$, cobalt $(5 \mathrm{~mm})$ and nickel ( $5 \mathrm{~mm}$ ) for the indicated amounts of time and immunoprecipitated with antiphosphotyrosine antibodies. In vitro kinase assays were performed as in the previous experiments, except that they were carried out in the presence of 1 rather than $10 \mu \mathrm{M}$ cold ATP. and Smith 1984). In vitro kinase assays after immunoprecipitation with antibodies specific for each of the nine src family members were performed. Increased kinase activity was found only in immunoprecipitates with antibodies specific for fyn, starting after $1 \mathrm{hr}$ of calciuminduced differentiation (Fig. 2; Table 1). These results were confirmed by in vitro kinase assays with poly/Glu/ Tyr) as an exogenous substrate (data not shown).

Immunoblotting with anti-fyn antibodies was used to measure amounts of this protein in total keratinocyte extracts as well as in anti-fyn immunoprecipitates at various times of calcium-induced differentiation. No induction of fyn protein expression was observed, which could explain the observed increase in fyn kinase activity (Fig. $3 \mathrm{~A}, \mathrm{~B}$; data not shown). A detailed time course experiment indicated that intrinsic fyn kinase activity was induced by $4 \mathrm{hr}$ of calcium treatment and increased up to four- to fivefold by $24 \mathrm{hr}$ (Fig. 3C). Similar results were obtained in a second independent experiment. fyn kinase activity was also induced by exposure of keratinocytes to intermediate calcium concentrations, such as 0.1 or 0.5 $\mathrm{mM}$, and was further induced at higher calcium doses (Fig. 3D). This response was specific for calcium, as other divalent cations such as cobalt or nickel failed to induce fyn kinase activity to any detectable extent (data not shown).

Given the partially overlapping effects of calcium and TPA on keratinocytes, it was of interest to determine whether fyn kinase activation is specific for calcium- induced differentiation or also occurs after TPA treatment. We found that the tyrosine kinase activity recovered after immunoprecipitation with the cst- 1 antiserum was significantly induced as early as $2 \mathrm{~min}$ after TPA treatment (Fig. 4). Such an activity persisted at elevated levels up to $6 \mathrm{hr}$. A similar increase in tyrosine kinase activity was observed after immunoprecipitation of TPA-treated keratinocytes with fyn specific antibodies (Fig. 4). In contrast to fyn, tyrosine kinase activity in yes immunoprecipitates was slightly decreased by $10 \mathrm{~min}$ utes of TPA exposure (Fig. 4). There was little or no effect on src kinase activity at these very early times of TPA exposure, and this activity was only slightly increased at later times (Fig. 4; data not shown). As with calcium, fyn protein amounts were not significantly affected by the TPA treatment (data not shown).

Thus, fyn kinase activity is progressively induced by exposure of keratinocytes to calcium, in a time- and dose-dependent fashion. In TPA-treated keratinocytes, the fyn kinase is also specifically activated, but with a much more rapid time of induction than in the calciumtreated cells.

Cortactin, a p80-85 substrate of src and fyn kinases, is tyrosine phosphorylated in keratinocytes in response to both calcium and TPA

It was previously reported that a protein of $\sim 80-85 \mathrm{kD}$ is increasingly tyrosine phosphorylated in primary kerati- 
Calautti et al.

Table 1. In vitro activity of specific tyrosine kinases in mouse keratinocyte differentiation

\begin{tabular}{|c|c|c|}
\hline \multirow[b]{2}{*}{ Kinase } & \multicolumn{2}{|c|}{ Calcium } \\
\hline & low & $\overline{\text { high }}$ \\
\hline$s r c$ & + & + \\
\hline fyn & + & +++ \\
\hline yes & + & + \\
\hline lck & - & - \\
\hline blk & - & - \\
\hline$f g r$ & + & + \\
\hline hck & + & + \\
\hline lyn & + & + \\
\hline yrk & + & + \\
\hline fak & + & + \\
\hline eck & + & - \\
\hline met & + & + \\
\hline$a b l$ & + & + \\
\hline
\end{tabular}

The listed tyrosine kinases were tested for their activity by in vitro assays with enolase as an exogenous substrate, after immunoprecipitation with kinase-specific antibodies (as described in Materials and methods|. Kinase activity was compared in keratinocytes under growing conditions and at various times of calcium-induced differentiation (10 $\mathrm{min}, 1,6,12$, and $24 \mathrm{hr}$ ). $1+$ and $-\mid$ The presence or absence, respectively, of basal activity levels detectable over background (in nonimmune control). $1+++\mid$ Increased activity relative to basal levels.

nocytes within 5-10' of TPA treatment and a few hours after calcium exposure (Filvaroff et al. 1990). A protein of similar molecular weight, cortactin, was previously identified as being highly tyrosine phosphorylated in cells expressing activated forms of src, fgr and fyn kinases (Wu et al. 1991; Wu and Parsons 1993). Keratinocyte cell extracts were immunoprecipitated with anticortactin antibodies followed by immunoblotting with either the same antibodies or antibodies against phosphotyrosine. While cortactin protein levels did not vary to any significant extent, tyrosine phosphorylation of this protein was strongly induced in response to both calcium and TPA (Fig. 5A). Enhanced tyrosine phosphorylation of cortactin was already evident by 10 minutes of TPA exposure (Fig. 5A). In response to calcium, cortactin became increasingly tyrosine phosphorylated after $1 \mathrm{hr}$ of exposure and, by $24 \mathrm{hr}$, phosphorylation levels were comparable to those found in src-transformed fibroblasts (Fig. 5B).

As we previously reported (Filvaroff et al. 1990), immunoblotting of total keratinocyte cell extracts with anti-phosphotyrosine antibodies showed induced phosphorylation of $\mathrm{a} \sim \mathrm{p} 80-85$ protein in the calcium-treated cells. Levels of the tyrosine phosphorylated $\mathrm{p} 80-85$ proteins were only marginally reduced by preclearing of the keratinocyte cell extracts with anti-cortactin antibodies, under conditions where cortactin itself was totally removed (Fig. 5C).

Thus, tyrosine phosphorylation of cortactin, a substrate of src- and fyn-related kinases, is induced in keratinocytes in response to both calcium and TPA, with a time course which is similar to that of fyn activation. Cortactin appears to be only one of a group of $\sim 80-85 \mathrm{kD}$ proteins which are tyrosine phosphorylated upon induction of keratinocyte differentiation.

Keratinocytes of fyn-negative mice exhibit an altered differentiation response under both in vitro and in vivo conditions

fyn activation may play a direct role in control of keratinocyte differentiation or, alternatively, may be a secondary event. To address this question, we compared the differentiation behavior of primary keratinocytes derived from fyn-negative mice with that of cells from wild-type
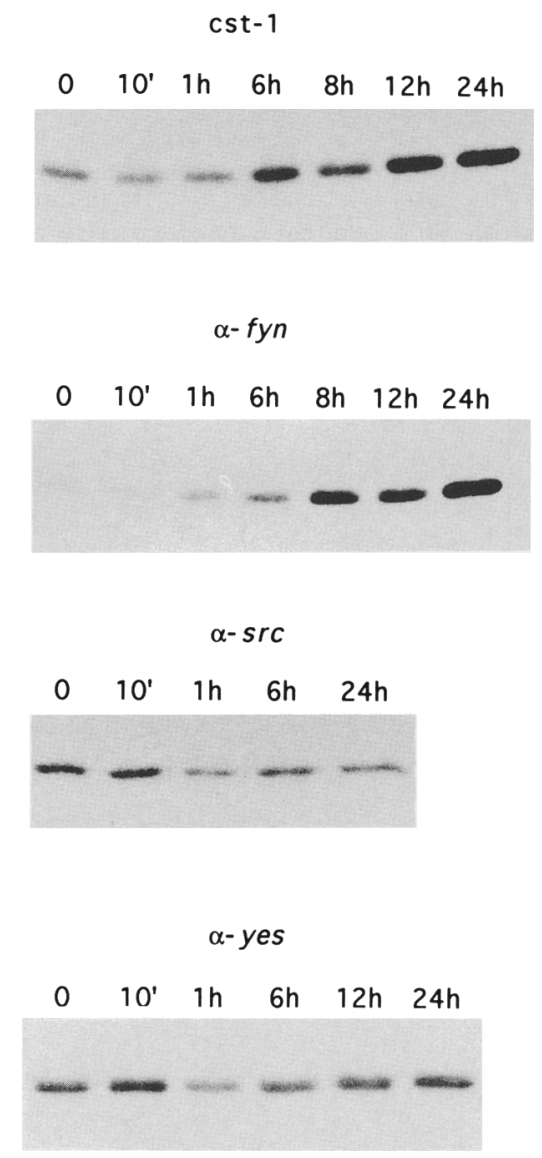

Figure 2. Tyrosine kinase activity associated with src-related kinases in calcium-treated keratinocytes. Extracts from keratinocytes at various times of calcium exposure were immunoprecipitated with wide specificity cst-l or fyn-, src-, and yes-specific antibodies and tested by in vitro kinase assay with enolase as an exogenous substrate. Reaction products were analyzed by gel electrophoresis and autoradiography (1 day of exposure). Densitometric analysis revealed a 1.2, 1.6, 2.9, 2.8 and 4.3-fold increase of enolase phosphorylation over basal levels in the $f y n$ immunoprecipitates from the $1,6,8,12$ and $24 \mathrm{hr}$ calciumtreated samples, respectively. Similar results were obtained in at least four independent experiments, except that the slight decrease in c-src activity shown here after $\mathrm{l} \mathrm{hr}$ of calcium exposure was not consistently observed. 
A

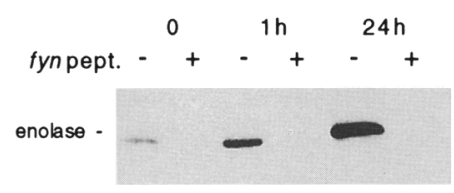

B

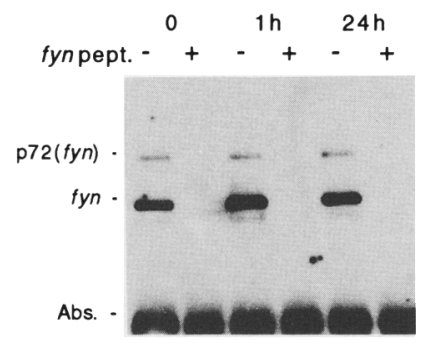

C

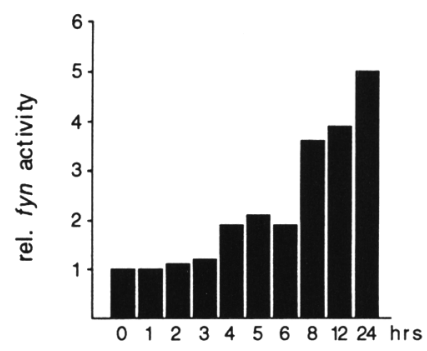

D

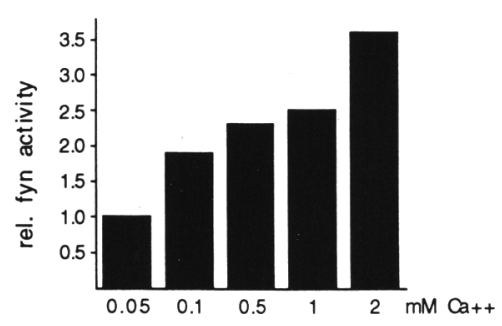

Figure 3. Induction of intrinsic fyn kinase activity by calcium treatment in a time- and dose-dependent fashion. Extracts from keratinocytes at various times of calcium exposure were immunoprecipitated with fyn-specific antibodies in the absence $(-)$ or presence $(+)$ of neutralizing peptide. The same immunoprecipitates were tested for in vitro kinase activity with enolase $(A)$ and for fyn protein levels by immunoblotting with fyn-specific antibodies $(B)$. The positions of $f y n$, of a $\mathrm{p} 72$ fyn- related protein (da Silva et al. 1993) and of immunoglobulins heavy chains (Abs.) are indicated. $(C)$ detailed time course of fyn kinase activation after calcium ( $2 \mathrm{mM}$ ) exposure. Extracts were immunoprecipitated with fyn-specific antibodies and processed for enolase kinase assay as in panel $A$ and for fyn immunoblot as shown in panel $B$. Intrinsic fyn kinase activity was determined as described in Materials and methods and expressed as fold of induction relative to basal fyn activity in untreated control cells. The graph shows one typical experiment. Similar results were obtained in another independent experiment. $(D)$ fyn kinase activation as a function of extracellular calcium concentrations. Primary keratinocytes were treated for $24 \mathrm{hr}$ with the indicated amounts of calcium, and fyn kinase activity was determined as described above. Values are expressed as fold of induction relative to basal fyn activity in untreated control cells. The graph shows one typical experiment. Similar results were obtained in three other independent experiments.

syngeneic controls. To address the issue of specificity, keratinocytes derived from yes-deficient mice were also examined.

Primary keratinocytes from the fyn or yes mutant mice grew into confluence to approximately the same time as the wild-type controls, indicating that the absence of either kinase has no severe effects on keratinocyte growth under our culture conditions. Morphologically, fyn-negative keratinocytes appeared less refractile than wild-type cells already under basal growing conditions (Fig. 6A,B). However, after TPA treatment, the differences between these two types of cells were more apparent; the mutant keratinocytes failed to assume the typical spindle morphology induced by TPA, and were much less refractile than the controls (Fig. 6C,D). Accentuated morphological differences were also found after calcium exposure, with the fyn-negative cells failing to stratify to any significant extent, and assuming a much larger size than their wild-type counterparts (Fig. 6E,F). Fluorescent staining for filamentous $(\mathrm{F}-)$ actin cables confirmed these differences in size, but failed to show any significant alterations in the actin cytoskeleton organization (Fig. 6G,H). These morphological differences were consistently observed with two independent preparations of fyn-negative and positive keratinocytes. Control experiments with wild-type cells under more sparse conditions were also performed to ensure that the observed morphological alterations of the fyn-negative keratinocytes were not simply due to cell density variations. The morphological features of the fyn-negative keratinocytes were also not observed with the yes-mutant cells (data not shown). cst-1
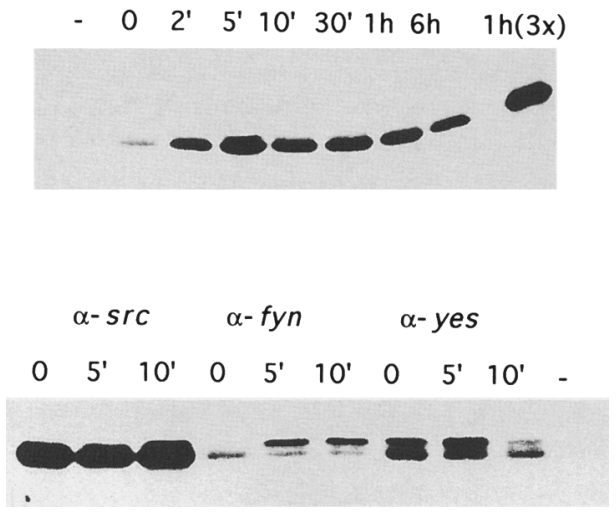

Figure 4. Tyrosine kinase activity associated with src-related kinases in TPA-treated keratinocytes. Extracts from keratinocytes at various times of TPA exposure $(100 \mathrm{ng} / \mathrm{ml})$ were immunoprecipitated with wide specificity cst-1 or fyn-, src- and yes-specific and control (-) antibodies and tested by in vitro kinase assay with enolase as an exogenous substrate. To verify that the assays were performed in antibody excess, three times more extracts of the $1 \mathrm{hr}$ TPA-treated cells [ $1 \mathrm{~h}(3 \times)]$ were also used for immunoprecipitation with the same amount of cst-1 antibodies used for the other samples. Reaction products were analyzed by SDS-gel electrophoresis and autoradiography (1-day exposure). Densitometric analysis revealed a 3.3 and 3.1-fold increase in enolase phosphorylation in the anti-fyn immunoprecipitates at $5^{\prime}$ and $10^{\prime}$ of TPA exposure, respectively. Similar results were obtained in two other independent experiments. 
Calautti et al.

A

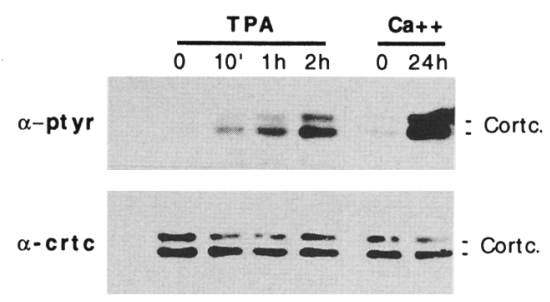

B

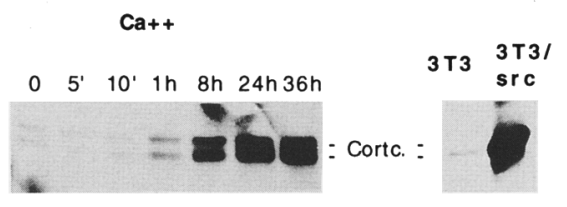

C

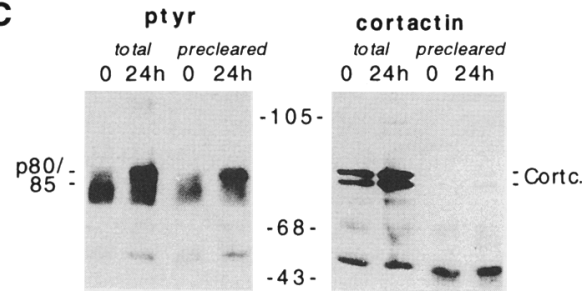

Figure 5. Tyrosine phosphorylation of cortactin in growing versus differentiating keratinocytes. $(A)$ Extracts from keratinocytes at various times of TPA $(100 \mathrm{ng} / \mathrm{ml})$ or calcium treatment $(2 \mathrm{mM}$ ) were immunoprecipitated with anti-cortactin antibodies or control antibodies $(-)$ and the immune complexes analyzed by SDS-polyacrylamide gel electrophoresis and immunoblotting with anti-phosphotyrosine antibodies ( $\alpha$-ptyr). The same blot was stripped and blotted with anti-cortactin antibodies $(\alpha$-crtc $) .(B)$ Detailed time course of cortactin tyrosine phosphorylation after calcium exposure. Samples were immunoprecipitated as described in $A$ and analyzed by anti-phosphotyrosine immunoblotting. Similar analysis was performed with untransformed (3T3) and v-src-transformed (3T3/src) NIH-3T3 fibroblasts. $(C)$ Extracts from keratinocytes under growing conditions and $24 \mathrm{hr}$ after calcium-induced differentiation were analyzed by immunoblotting with anti-phosphotyrosine or anticortactin antibodies. Total cell extracts were used directly (total) or after preclearing by immunoprecipitation with anticortactin antibodies (precleared). The blots were developed with the ECL system (Amersham).

Biochemically, treatment with calcium-induced tyrosine phosphorylation of a number of proteins, including the p80/85 group, in both wild-type and yes mutant keratinocytes, while no such induction was observed in the fyn-negative cells (Fig. 7, upper panel). Similarly, TPA-induced phosphorylation of the $\mathrm{p} 80 / 85$ proteins was specifically blocked in the fyn-negative keratinocytes (Fig. 7, lower panel).

Epidermal transglutaminase is a well characterized enzymatic marker of keratinocyte differentiation (Thacer and Rice 1985), which is induced in cultured keratinocytes in response to both calcium and TPA, and which is blocked by concomitant treatment with tyrosine ki- nases inhibitors (Filvaroff et al. 1990). In agreement with these previous findings, enzymatic measurements revealed very little or no induction of transglutaminase activity in calcium- and TPA-treated fyn-negative keratinocytes, while this enzyme was readily induced in the wild-type controls (Fig. 8).

Differentiation markers of the intermediate and upper epidermal layers such as keratin 1, involucrin and filaggrin were previously reported to be induced in primary mouse keratinocytes by calcium treatment (Yuspa et al. 1989). Exposure of control cells to $2 \mathrm{~mm}$ calcium caused a strong induction of keratin 1 , involucrin and filaggrin expression by $12 \mathrm{hr}$ (Fig. 9). These markers were also induced in the yes-mutant keratinocytes. In contrast, in

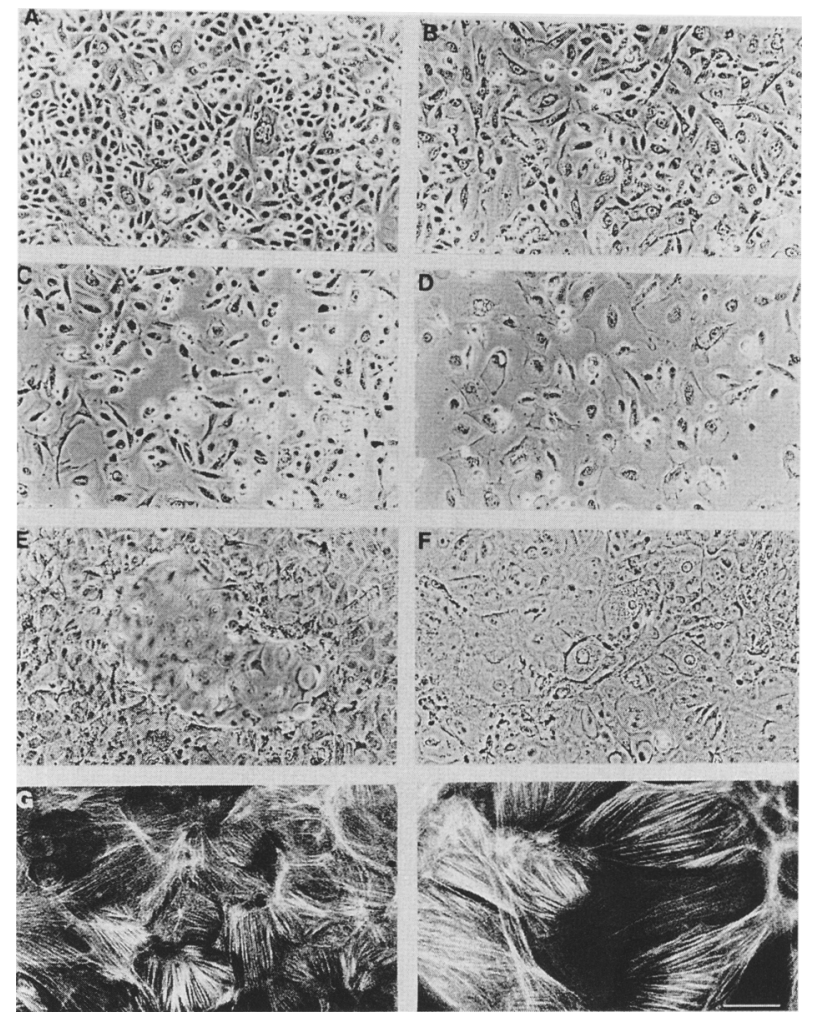

Figure 6. Morphological and actin cytoskeletal characteristics of control and fyn-negative keratinocytes under growing and differentiating conditions. Primary mouse keratinocytes from fyn-negative mice and genetically-matched controls were grown to confluence in low calcium medium and analyzed under basal conditions and at $24 \mathrm{hr}$ after calcium- or TPA-induced differentiation. $(A-F)$ Contrast phase microscopy of primary keratinocytes derived from control and fyn-null mice. $(A, B)$ Control and fyn-negative keratinocytes in low calcium medium. $(C, D)$ Control and fyn-negative keratinocytes after $24 \mathrm{hr}$ of TPA exposure. $(E, F)$ Control and fyn-negative keratinocytes after 24 hr of calcium exposure (area out of focus in panel $E$ is due to the presence of focal stratification which was observed throughout the cultures of control but not of fyn-negative keratinocytes). $(G, H)$ Control and fyn-negative keratinocytes $24 \mathrm{hr}$ after calcium exposure, after F-actin staining and visualization by confocal microscopy. Bar, $15 \mu \mathrm{m}$ for $A-F$ and $5 \mu \mathrm{m}$ for $G$ and $H$. 


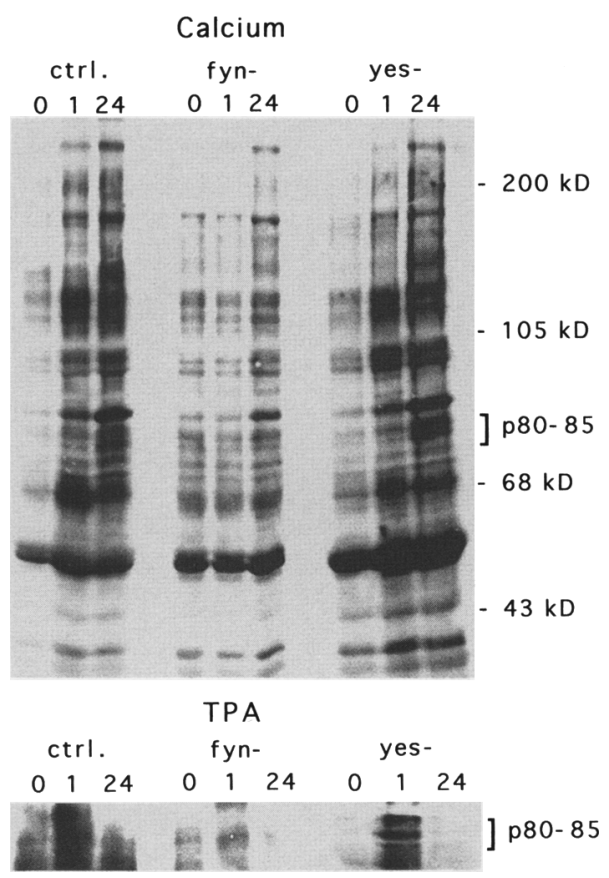

Figure 7. Induction of tyrosine phosphorylation by calciumand TPA-treatment of wild-type, fyn- and yes-deficient keratinocytes. Primary keratinocytes derived from fyn-deficient (fyn-), yes-deficient (yes-) and syngenic control mice (Ctrl.) were exposed to calcium $(2 \mathrm{mM})$ or TPA $(100 \mathrm{ng} / \mathrm{ml})$ for the indicated amounts of time. Extracts were normalized for protein concentration and analyzed by gel electrophoresis $17.5 \%$ SDS-PAGE) and immunoblotting with anti-phosphotyrosyne antibodies. The immunoblot was developed with the ECL system (Amersham). The position of the molecular weight markers and of the $\mathrm{p} 80-85$ proteins are indicated.

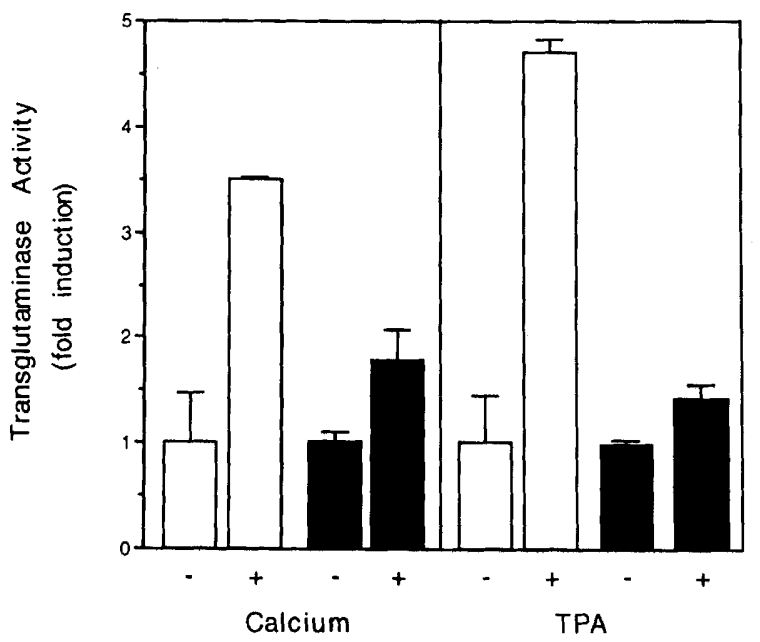

Figure 8. Transglutaminase induction in control and fyn-null keratinocytes. Transglutaminase activity was measured in duplicate cultures of primary keratinocytes from fyn-negative mice (black bars) and wild-type controls (white bars), under basal conditions and $24 \mathrm{hr}$ after calcium or TPA exposure. Transglutaminase activity is expressed as folds of induction in treated versus untreated cells. Similar results were obtained in two other independent experiments.
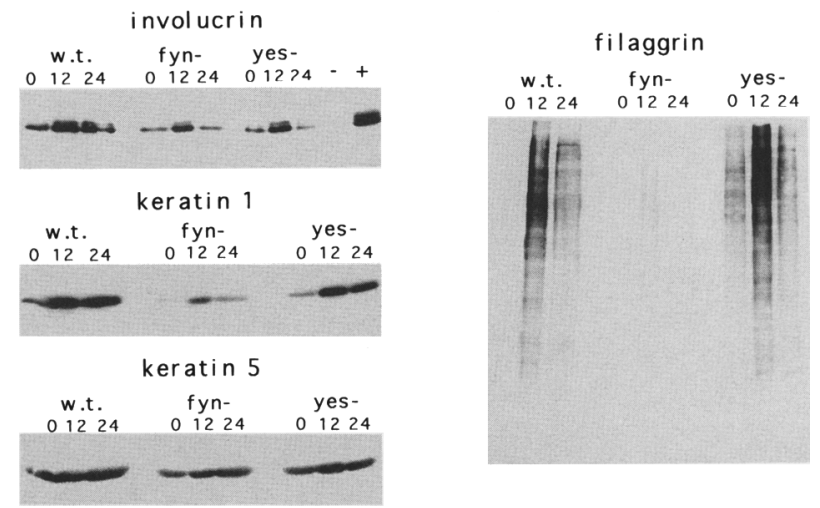

Figure 9. Induction of differentiation markers by calcium treatment of control and fyn- and yes-deficient keratinocytes. Primary keratinocytes from wild-type controls (w.t.), fyn-null, (fyn -) and yes-deficient (yes - ) mice were kept under growing conditions in low calcium medium $\{0\}$, or induced to differentiate by calcium ( $2 \mathrm{~mm}$ ) for $12 \mathrm{or} 24 \mathrm{hr}$. The cells were lysed in boiling sample buffer and the extracts were normalized for protein content. Equal amount of proteins were separated on a $7.5 \%$ SDS-PAGE, and the expression of keratinocyte differentiation markers was analyzed by immunoblotting with specific antibodies. The same blot was probed with anti filaggrin antibodies, anti-keratin 1 and anti-keratin 5 as a loading control. The same protein extracts were run on a second identical gel for the involucrin immunoblot, alongside immunoprecipitates with involucrin-specific antiserum $(+)$ or rabbit normal serum $(-)$. Control experiments with cell extract preparations under different reducing conditions, as well as immunofluorescence analysis suggested that the lesser induction of filaggrin and involucrin at $24 \mathrm{hr}$ of calcium treatment may be due to trapping of these proteins in insoluble cross-linked products formed during the differentiation process.

the fyn-negative cells, induction of filaggrin expression was almost totally suppressed, and that of keratin 1 was strongly reduced (Fig. 9). Only involucrin induction occured to a similar extent in fyn-and yes-deficient cells, and was only slightly reduced relative to the control (Fig. 9). Expression of keratin 5 in cultured mouse keratinocytes is not affected by calcium-induced differentiation. Immunoblotting of the same extracts tested above with anti-K5 antibodies verified that equal amounts of proteins were tested in each case (Fig. 9). In agreement with these changes in cultured cells, keratin 1 and filaggrin were found to be expressed in a significantly reduced number of epidermal layers in newborn fyn-negative mice relative to either yes-mutant or wild-type animals (Fig. 10). Expression of keratin 5 and involucrin appeared similar in all cases.

Thus, fyn null keratinocytes are altered in their differentiation response to both calcium and TPA. These effects appear to be specific as they were not observed in keratinocytes carrying a disruption of the related yes kinase gene. In parallel with these findings, the skin of fyn-negative mice exhibit reduced expression of specific keratinocyte differentiation markers. 
w.t.

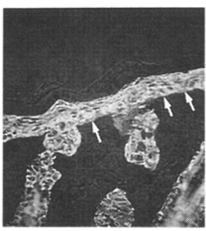

k1

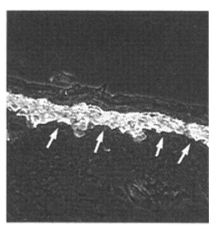

fil.
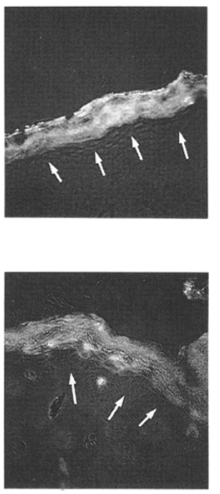

fyn-/-
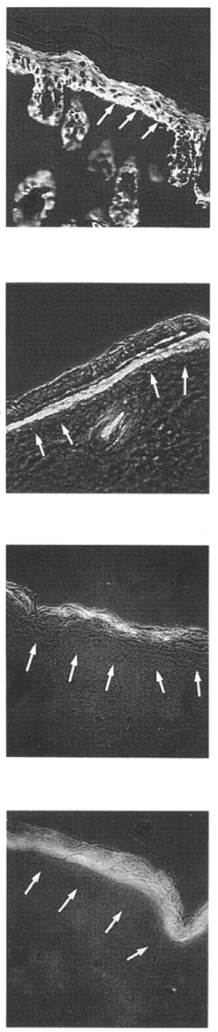

yes-1-
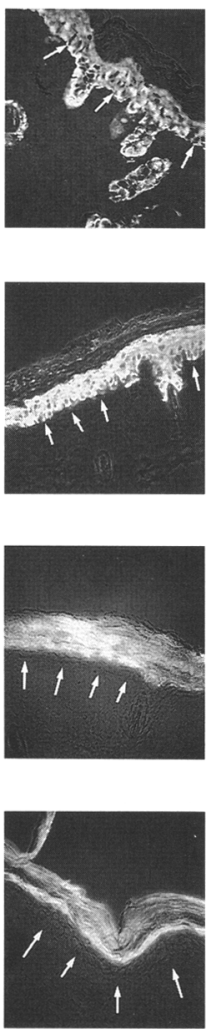

Figure 10. Analysis of keratinocyte differentiation markers in the skin of control, fyn- and yes-mutant mice. Frozen sections of the skins of 3-day-old mice were analyzed by immunofluorescence analysis with antibodies directed against mouse keratin 5, keratin 1, profilaggrin and involucrin. Phase contrast and immunofluorescence images were taken with a Zeiss Axiovert microscope $(32 \times)$. In each case, the position of the basal epidermal layer is indicated (white arrows). Similar results were obtained in a second independent experiment.

\section{Discussion}

We have demonstrated that induction of keratinocyte differentiation by calcium and TPA is associated with induction of two distinct tyrosine kinase activities. One activity, recovered in anti-phosphotyrosine immunoprecipitates, is specifically induced by calcium, and a number of other divalent cations, and does not correspond to any of the known tyrosine kinases that were tested. The second activity is induced in response to both calcium and TPA, and has been identified as the fyn kinase. In close parallel with fyn activation, cortactin, a p80-85 substrate of $s r c$ and fyn kinases found in association with actin at discrete membrane sites, becomes increasingly tyrosine phosphorylated in calcium- and TPA-treated keratinocytes. Finally, keratinocytes derived from fyn-but not yes-deficient mice are significantly altered in their differentiation response to both of these agents.

Several findings suggest that the calcium-induced kinase activity which was recovered after anti-phosphotyrosine immunoprecipitation is the one responsible for phosphorylation of the ras-GAP-associated p62 protein in vivo (Filvaroff et al. 1992). Both kinase activation and p62 phosphorylation occur in keratinocytes within $2^{\prime}-5^{\prime}$ of calcium exposure, specifically in response to this agent and not to TPA, and are not induced by calcium in calcium-resistant keratinocyte variants nor in fibroblasts (Filvaroff et al. 1990, 1992; E. Calautti and G.P. Dotto, unpubl.). Furthermore, both p62 phosphorylation and tyrosine kinase activity are induced by a number of other divalent cations, while neither of them is induced by calcium ionophores (Filvaroff et al. 1994; this paper). These observations indicate that tyrosine kinase activation in differentiating keratinocytes is not triggered by a simple increase of intracellular calcium and may occur through an indirect calcium-sensor mechanism (Filvaroff et al. 1994). Consistent with this possibility, the tyrosine kinase activity found in anti-phosphotyrosine immunoprecipitates is not activated by direct addition of calcium to the in vitro reactions (E. Calautti and G.P. Dotto, unpubl.). Detailed characterization of this activity will have to wait for its identification.

A second tyrosine kinase activity activated after $1 \mathrm{hr}$ of calcium-induced differentiation was recovered after immunoprecipitation with $f y n$-specific antibodies. This increased activity was not due to increased fyn protein expression. More difficult to rule out is the possibility that the increased activity is due to a kinase which closely associates with fyn, rather than to fyn itself. In fact, fyn has been shown to associate with at least two membrane-bound tyrosine kinases, the PDGF (Kypta et al. 1990) and CSF-1 (Courtneidge et al. 1993) receptors, as well as to a cytoplasmic kinase, fak (Cobb et al. 1994). This latter kinase is intimately connected with cell adhesion/membrane structures which could be among the primary targets of calcium- and TPA-induced differenti-

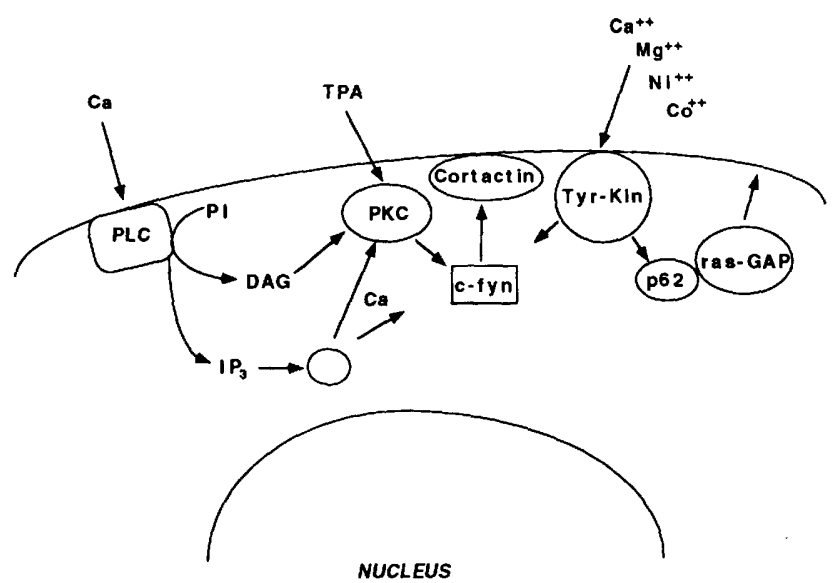

Figure 11. Membrane and cytoplasmic signal transduction events involved in control of mouse keratinocyte differentiation. This model is based on the data presented in this paper as well as on published material, as discussed in detail in the text. Some of the connections that we have drawn are still tentative but provide a useful working hypothesis for further work in this system. 
ation. However, anti-phosphotyrosine immunoblotting of anti-fak immunoprecipitates as well as direct in vitro kinase assays indicated that $f a k$ is not activated upon induction of keratinocyte differentiation (Table 1). Also, immunoblotting of anti-phosphotyrosine immunoprecipitates from growing and differentiating keratinocytes with anti-fyn antibodies failed to reveal any close association of fyn with other tyrosine phosphorylated proteins, under conditions where the tyrosine kinase activated at very early times of calcium treatment is readily recovered. Intrinsic activation of fyn kinase activity in vivo is strongly suggested by the intense tyrosine phosphorylation of its cortactin substrate, which occurs in both calcium- and TPA-treated keratinocytes, as well as by our results with the fyn-negative cells (see below).

It has been recently reported that the c-src kinase is activated and c-yes inhibited in human keratinocytes induced to differentiate by the concomitant treatment with calcium and calcium ionophore A23187 (Zhao et al. 1992, 1993). It is difficult to relate these results with ours, given the different sensitivity of human and mouse keratinocytes to calcium. The specific molecules which become tyrosine phosphorylated in vivo after induction of mouse keratinocyte differentiation, such as p62 and $\mathrm{p} 80 / 85$, were not found in the human keratinocytes (Zhao et al. 1992; E. Calautti and G.P. Dotto, unpubl.). The A23187 calcium ionophore used to induce differentiation of the human cells has a number of calcium-unrelated effects and inhibits, rather than stimulating, tyrosine phosphorylation in differentiating mouse keratinocytes (Filvaroff et al. 1994). Furthermore, the effects on src and yes activity elicited by A23187 are not specific for keratinocytes, as they were also observed in similarly treated fibroblasts (Zhao et al. 1993).

Treatment of mouse keratinocytes with TPA did not cause an increase in tyrosine kinase activity which is immunoprecipitated by anti-phosphotyrosine antibodies. Instead, treatment with this compound induced activation of the fyn kinase, at much earlier times than those observed with calcium. The rapid induction of fyn activity (within 2 min of TPA exposure) suggest that this kinase could be directly activated by PKC action. This may represent a novel mechanism of PKC-mediated activation of src-related kinases. In fact, treatment of Jurkat $T$ cells with TPA was also reported to cause rapid phosphorylation of the lck kinase, on a number of serine and threonine residues, but in that case lck kinase was not activated (Luo and Sefton 1990). Conversely, treatment of neuronal (Bjelfman et al. 1990) or myeloid (Gee et al. 1986) cells with TPA was shown to cause c-src activation but only at late times, through some indirect mechanisms which result, respectively, in increased c-src phosphorylation (mostly on Ser 12) or synthesis.

The molecular mechanisms responsible for fyn activation in keratinocyte differentiation remain to be elucidated. Preliminary results indicate that in calcium- but not TPA-treated keratinocytes a fyn peptide containing tyrosine 531 is specifically dephosphorylated. fyn activity is negatively regulated by phosphorylation of this residue, which is analogous to src Tyr 527 (Cheng et al.
1991; Cooper and Howell 1993|. A possible mechanism by which fyn activation could be selectively achieved could be activation of a specific protein tyrosine phosphatase located in close proximity of the fyn kinase. This situation would be analogous to that described in T cells, where a transmembrane tyrosine phosphatase, CD45, has been shown to regulate activity of the fyn kinase associated with the T cell receptor (Hurley et al. 1993).

Cortactin was originally identified in src- (and fgr-and fyn-) transformed cells, as a heavily tyrosine phosphorylated $\mathrm{p} 80-85$ protein which colocalizes with F-actin at specific sites of cell contact (podosomes or rosettes) (Wu et al. 1991). The multidomain structure of this protein, together with its cellular localization suggest that it may play a role in cytoskeleton/membrane organization. In normal cells, cortactin is phosphorylated mostly on serine and threonine, and is also found in association with F-actin at peripheral cell extensions. Tyrosine phosphorylation of cortactin, also found in growth factorstimulated cells (Downing and Reynolds 1992; Maa et al. 1992; S. Wong et al. 1992), does not affect its actin-binding properties (Wu and Parsons 1993), but may influence its association with other structural or signal transducing proteins. In keratinocytes, cortactin becomes increasingly tyrosine phosphorylated in response to both calcium and TPA, at times which closely coincide with those of fyn activation. The specific connection between phosphorylation of this protein and structural changes associated with keratinocyte differentiation is currently under investigation.

fyn-negative keratinocytes appeared significantly different from control cells after induction of differentiation by calcium and TPA. These morphological/ structural changes were associated with-and could be explained by-decreased or absent induction of phosphorylation of a number of proteins, including the p80-85 group, in the fyn-negative cells. A strong indication that the fyn kinase plays an important and specific role in control of keratinocyte differentiation is provided by the decreased induction of a number of differentiation markers in fyn-, but not yes-mutant keratinocytes. The latter cells were derived from mice carrying a disruption of the yes gene, such that yes kinase activity is totally abrogated. These mice express a truncated form of the yes protein at low levels and only in certain tissues. This truncated yes protein lacks an essential region of the kinase domain and could only act, if at all, as a dominant-negative mutant interfering with the function of other $\mathrm{SH} 2$ - and SH3-containing proteins. In keratinocytes, this clearly does not happen, as the yes-mutant cells behave like the wild-type controls.

The biological relevance of our findings with cultured cells is further substantiated by the fact that in vivo, expression of these markers is significantly reduced in several overlying epidermal layers of newborn mice with a disruption of the fyn-, but not yes-kinase gene. Similar alterations would be much harder if not impossible to assess in adult mice, because their epidermis is much thinner, consisting only of two or three keratinocyte layers. Functionally, the skin of adult fyn-negative mice 
produced a normal hyperplastic response to acute TPA treatment (E. Calautti and G.P. Dotto, unpubl.). In view of the subtle changes that have been previously detected in the immune and nervous systems of these mice (Appleby et al. 1992; Stein et al. 1992; Grant et al. 1992), it is likely that a finer analysis will be required to find functional abnormalities in the skin of these animals. Additionally, the previous studies suggest that compensatory activation of other src-related kinases can also take place. Future work will have to address these possibilities, by extending the present analysis to the skin of mice where multiple src-related genes have been eliminated.

In conclusion, we have demonstrated that two distinct tyrosine kinase activities are induced at very early times of keratinocyte differentiation, and at least one of them, fyn, is directly involved in control of this process. These results can be integrated with previous findings on control of keratinocyte differentiation by calcium and TPA, in the following model (Fig. 11). Treatment of keratinocytes with calcium triggers the very rapid activation of a tyrosine kinase which is in turn responsible for the phosphorylation of the ras-GAP associated p 62 protein. Activation of this kinase and phosphorylation of $\mathrm{p} 62$, are specifically induced by calcium and a number of other divalent cations, and are not linked to increased levels of intracellular calcium, suggesting that a cation-specific receptor, similar to that of other calcium-responsive cells, is involved (Filvaroff et al. 1994).

Besides its direct and specific effects on this pathway, calcium causes phospholipase $\mathrm{C}$ activation, a rapid increase in phosphatidylinositol metabolism, subsequent intracellular calcium mobilization and protein kinase C activation (Yuspa 1994). This sequence of events may ultimately lead to activation of the fyn kinase, possibly through decreased phosphorylation of its negative regulatory tyrosine. fyn activation is in turn responsible for the phosphorylation of a group of $\mathrm{p} 80 / 85$ proteins, among which cortactin may be involved in specific changes at the cytoskeleton/membrane junction. Treatment of keratinocytes with TPA does not activate the calcium-specific pathway which leads to $\mathrm{p} 62$ phosphorylation. Instead, it activates fyn, possibly through a direct PKC mechanism which bypasses many of the steps induced by calcium. Even in this case, fyn activation leads to cortactin phosphorylation on tyrosine. A clearly outstanding question is how these changes are connected with specific gene expression events involved in the keratinocyte terminal differentiation process.

\section{Materials and methods \\ Cells}

Primary keratinocytes were isolated from newborn Sencar mice and cultivated in minimal essential medium with $4 \%$ Chelextreated fetal calf serum (Hyclone), epidermal growth factor (EGF; $10 \mathrm{ng} / \mathrm{ml}$, Collaborative Research, Inc., Cambridge, MA), and $0.05 \mathrm{mM} \mathrm{CaCl}_{2}$ (low calcium medium), as described (Hennings et al. 1980; Filvaroff et al. 1990). For all experiments, cells were used one week after plating. Culture medium was changed for the last time $24 \mathrm{hr}$ before the experiment. Keratinocyte differentiation was induced by addition of $\mathrm{CaCl}_{2}$ (to $2 \mathrm{mM}$ ) or TPA (100 $\mathrm{ng} / \mathrm{ml}_{;}$stored in aliquots of $100 \mu \mathrm{g} / \mathrm{ml}$ in DMSO at $-70^{\circ} \mathrm{C}$; purchased from Sigma). A23187 was purchased from Molecular Probes and stored in aliquots of $1 \mathrm{~mm}$ in DMSO at $-70^{\circ} \mathrm{C}$.

\section{Antibodies}

Anti-phosphotyrosine mAbs Py20 (Glenney et al. 1988) used for immunoprecipitations were purchased from ICN. Anti-phosphotyrosine mAbs 4Gl0 (Druker et al. 1989) used for immunoblots were from Upstate Biotechnology Inc. Cst-1 antibodies (Courtneidge and Smith 1984) were a gift of Dr. Sara Courtneidge (EMBL, Heidelberg, Germany); anti-src M327 monoclonals (Lipsich et al. 1983) were provided by Dr. Joan Brugge (Ariad Pharmaceuticals, Cambridge, MA.). Anti-fyn affinity purified rabbit immunoglobulins (epitope: amino acids 28-48 of human p5 $9^{\text {fyn }}$ and fyn neutralizing peptide were purchased from Santa Cruz Biotechnology, Inc. Anti-yes and anti-yrk sera (Zhao et al. 1991; Sudol et al. 1993) were a gift of Dr. Marius Sudol (The Rockefeller University, New York). Polyclonal antisera against unique sequences of lyn, fgr and hck (Huang et al. 1991) were a gift of Dr. Joseph Bolen (Bristol-Myers Squibb Pharmaceutical Research Institute, Princeton, NJ). Affinity-purified antiserum against residues $22-51$ of $l c k$ was purchased from UBI. Anti-blk serum was provided by Dr. Steve Desiderio (Johns Hopkins University, Baltimore, MD). Anti-cortactin (p80-85) monoclonal antibodies 4F11 (Kanner et al. 1990) were a gift of Dr. Thomas Parsons /University of Virginia Health Sciences Center, Charlottesville, VA). Anti-fak monoclonal antibodies (Kanner et al. 1990) were purchased from UBI. Anti-met antibodies were purchased from UBI; anti-abl antibodies were purchased from Oncogene Science. Anti-involucrin antiserum (Djian et al. 1993) was purchased from Berkeley Antibodies Company (Richmond, CA). Affinity-purified polyclonal antibodies anti-filaggrin, antikeratin 1 and anti-keratin 5 were a gift of Dr. Stuart Yuspa (National Institutes of Health, Bethesda, MD).

\section{Immunoprecipitations}

Mouse primary keratinocytes were washed twice in PBS containing $1 \mathrm{mM} \mathrm{Na}_{3} \mathrm{VO}_{4}$ and then lysed in RIPA buffer $(1 \%$ Triton $\mathrm{X}-100,1 \%$ sodium deoxycholate, $0.1 \%$ SDS, $150 \mathrm{~mm} \mathrm{NaCl}$ ) supplemented with $1 \mathrm{~mm}$ phenylmethylsulfonylfluoride, $1 \mathrm{~mm}$ $\mathrm{Na}_{3} \mathrm{VO}_{4}, 10 \mu \mathrm{g} / \mathrm{ml}$ aprotinin (Sigma), $10 \mu \mathrm{g} / \mathrm{ml}$ leupeptin (Sigma) for $20^{\prime}$ on ice. Cell lysates were spun for $5^{\prime}$ at $4^{\circ} \mathrm{C}$. Samples were normalized for equal amounts of proteins $(100$ $300 \mu \mathrm{g}$ ) by a Bradford assay (Bio-Rad), and incubated for $2 \mathrm{hr}$ at $4^{\circ} \mathrm{C}$ with antibodies. Monoclonal antibodies $(1-2 \mu \mathrm{g})$ or affinitypurified antisera, or $2-5 \mu$ l of total immune serum were used for single immunoprecipitation reaction. Affinity-purified rabbit anti-goat IgG $(1-2 \mu \mathrm{g})$ (Cappel, West Chester, PA) or $2-5 \mu$ of rabbit normal serum were used for the nonimmune controls. Protein A-Sepharose (60 $\mu$ l of a $50 \%$ suspension; Pharmacia) in RIPA buffer was added and samples were incubated for other $30^{\prime}$ at $4^{\circ} \mathrm{C}$. Protein A-Sepharose precoupled with affinity-purified rabbit anti-mouse antiserum (Pierce) was used for immunoprecipitation with M327 and 4F11 mAbs.

\section{Kinase assays}

Immune complexes for kinase assay were washed twice in RIPA buffer, twice in kinase buffer $(20 \mathrm{~mm}$ HEPES at $\mathrm{pH} 7.4 ; 3 \mathrm{~mm}$ $\left.\mathrm{MnCl}_{2}, 5 \mathrm{mM} \mathrm{MgCl}_{2}\right)$, resuspended in $50 \mu \mathrm{l}$ of kinase buffer supplemented with $5 \mu \mathrm{Ci}$ of $\gamma^{32} \mathrm{P}$ ATP $(6000 \mathrm{Ci} / \mathrm{mM}$; NEN), 1 $\mu \mathrm{M}$ ATP, and $5 \mu \mathrm{g}$ of acid-denatured enolase and incubated at 
$30^{\circ} \mathrm{C}$ for $10^{\prime}$. In some experiments the concentration of cold ATP was $10 \mu \mathrm{M}$. All reactions were stopped with $25 \mathrm{~mm}$ cold ATP, 20 mM EDTA. Samples incubated with enolase were supplemented with $2 \times$ sample buffer, boiled and separated on $10 \%$ SDS-PAGE. The gels were fixed in 10\% acetic acid: $10 \%$ methanol, and washed several times with $10 \%$ acetic acid to remove unincorporated label. The position of the substrate was detected by coomassie blue staining. Quantitative mesurements of fyn kinase activity were performed as follows: Enolase bands were excised from gels and $\gamma-{ }^{32} \mathrm{P}$ incorporation was determined by scintillation counting. fyn protein levels were determined by immunoblotting of the same immunoprecipitates tested for kinase assay with anti-fyn antibodies, using iodinated protein $\mathrm{A}$ as a detection agent. The autoradiograms of the immunoblots were subjected to densitometric analysis using a Molecular Dynamics computing densitometer and the data were processed with a Fast Scan ImageQuant software version 3.0 (Molecular Dynamics). Specific kinase activity was calculated as amounts of $\gamma^{32}$ incorporation into the enolase substrate per amount of fyn protein present in each immunoprecipitate. Values were expressed as fold of induction relative to basal fyn activity in control cells.

\section{Immunoblotting}

Immune complexes processed for immunoblotting were washed four times in RIPA buffer with inhibitors, then eluted in boiling sample buffer for $3 \mathrm{~min}$ and separated electrophoretically on $7.5 \%$ or $10 \%$ SDS-PAGE alongside 12 - to $200-\mathrm{kD}$ molecular size markers (GIBCO). Immunoblotting of protein gels onto nitrocellulose was performed as previously described (Filvaroff et al. 1990). The transfer buffer and the procedures for blocking and washing the filter were described (Kamps and Sefton 1988). Blots were developed with $1 \mu \mathrm{Ci} / \mathrm{ml}$ of ${ }^{125} \mathrm{I}$-labeled protein A $(35 \mu \mathrm{Ci} / \mu \mathrm{g}$; ICN) in blocking buffer and exposed for $24-48 \mathrm{hr}$.

For anti-phosphotyrosine immunoblots, horseradish peroxidase-conjugated anti-mouse immunoglobulins (Amersham) were used as secondary antibodies in a 1:5000 dilution, and blots were developed with the ECL system (Amersham).

\section{Phosphoamino acid analysis}

${ }^{32} \mathrm{P}$-labeled proteins were transferred to Immobilon-P membrane (Millipore). Filters were exposed for $2-4 \mathrm{hr}$, and the bands of interest were excised and subjected to hydrolysis by boiling in $5.7 \mathrm{~N} \mathrm{HCl}$ for $1 \mathrm{hr}$. Before electrophoresis samples were supplemented with a mixture of cold phosphoserine, phosphothreonine and phosphotyrosine as standards. The resulting phosphoamino acids were resolved by two-dimensional electrophoresis as described by Kamps and Sefton (1989). The position of the standards was determined by Ninhydrin staining.

\section{Actin staining of primary keratinocytes}

Primary mouse keratinocytes were fixed for $5^{\prime}$ at $37^{\circ} \mathrm{C}$ with $2 \%$ paraformaldheyde in PBS, permeabilized with $0.4 \%$ Triton X-100, washed with PBS and incubated for 60 min with Bodipy 581-591 phalloidin (Molecular Probes, Inc., Eugene, OR), 5 $\mathrm{U} / \mathrm{ml}$ in PBS. The cells were washed four times for $5^{\prime}$ in PBS and visualized by laser confocal microscopy (BioRad MRC 600 Confocal Imaging System, attached to a Zeiss Axiovert microscope).

\section{Transglutaminase assay}

Primary keratinocytes were prepared from three days old fynnegative mice (Stein et al. 1992) and from control mice of the same age and same genetic background (C57Bl/129). Cells were plated onto $35-\mathrm{mm}$ dishes, grown to confluence and tested at one week of plating, $24 \mathrm{hr}$ after addition of fresh low calcium medium, or medium plus calcium $(2 \mathrm{~mm})$ or TPA $(100 \mathrm{ng} / \mathrm{ml})$. Transglutaminase activity was assayed in duplicate samples, by measuring the incorporation of $\left[2,3{ }^{3} \mathrm{H}\right]$ putrescine $(31.1 \mathrm{Ci} /$ mmole; Dupont, NEN) into casein at $\mathrm{pH} 9.5$, as described by Filvaroff et al. (1990). Background radioactivity was determined from control reactions containing no cell lysate, and was subtracted in each case. Experimental values were normalized for protein amounts (Bradford assay; Bio-Rad Laboratories, Richmond, CA) and expressed as folds of induction in treated versus untreated cells.

\section{Immunofluorescence of newborn mouse skins}

Unfixed frozen sections $(6 \mu \mathrm{m})$ of three day old newborn mice were air dried before staining. After three PBS washes, the sections were blocked with goat normal serum diluted 1:5 in PBS for $30 \mathrm{~min}$ at room temperature. Sections were treated with the avidin/biotin blocking solution (Vector) according to the manufacturer's instruction, and then incubated with the appropriate antibody diluted in $0.3 \%$ Triton X-100, $1 \%$ BSA in PBS (buffer A) for $2 \mathrm{hr}$ at room temperature. The slides were then washed in PBS and incubated for $1 \mathrm{hr}$ with biotinylated goat anti-rabbit IgG (Vector) diluted 1:1000 in buffer A. After several PBS washes the sections were incubated for $30 \mathrm{~min}$ with fluoresceinconjugated streptavidin (Amersham) diluted 1:100 in buffer A, washed extensively in PBS and mounted with $0.1 \mathrm{M} n$-propylgallate in glycerol. The slides were examined with a Zeiss Axiovert microscope.

\section{Acknowledgments}

We are grateful to Drs. Joan Brugge, Sara Courtneidge, Marius Sudol, Joseph Bolen, Steve Desiderio, Thomas Parsons, and Stuart H. Yuspa for their gifts of antibodies and Dr. Philippe Soriano for making available the fyn negative mice. We are indebted to Dr. David Stern for his advice in the initial part of this project; Dr. Bernard Ortel for his help with the immunofluorescence and morphological studies; and Dr. Arpad Molnar for his suggestions. We thank Drs. Janice Brissette, David Stern, Sheila M. Thomas, and Philippe Soriano for critical reading of the manuscript and Mr. Robert Little for skilfull technical support. This work was supported by National Institutes of Health Grants AR39190 and CA16038 to G.P.D.

The publication costs of this article were defrayed in part by payment of page charges. This article must therefore be hereby marked "advertisement" in accordance with 18 USC section 1734 solely to indicate this fact.

\section{Note added in proof}

Like yes-deficient keratinocytes, primary keratinocytes derived from $s r c$-negative mice (kindly provided by Dr. Pat Preisig) were found to be indistinguishable from wild-type controls in their differentiation response, as evaluated by morphological characteristics, tyrosine phosphorylation pattern, and differentiation marker expression.

\section{References}

Appleby, M.W., J.A. Gross, M.P. Cooke, S.D. Levin, X. Qian, and R.M. Perlmutter. 1992. Defective T cell receptor signaling in mice lacking the thymic isoform of $\mathrm{p} 59^{\mathrm{fyn}}$. Cell 70: 751-763. 
Bjelfman, C., G. Meyerson, C.A. Cartwright, K. Mellstrodöm, U. Hammerling, and S. Pahlman. 1990. Early activation of endogenous pp $60^{\text {src }}$ kinase activity during neuronal differentiation of cultured human neuroblastoma cells. Mol. Cell. Biol. 10: 361-370.

Bolen, J.B. 1993. Nonreceptor tyrosine protein kinases. Oncogene 8: 2025-2031.

Brickell, P.M. 1992. The p60 $0^{\text {c-src }}$ family of protein-tyrosine kinases: Structure, regulation, and function. Crit. Rev. Oncogenesis 3: 401-446.

Cheng, S.H., P.C. Espino, J. Marshall, R. Harvey, J. Merrill, and A.E. Smith. 1991. Structural elements that regulate pp59 $9^{\text {c-fyn }}$ catalytic activity, transforming potential, and ability to associate with Polyomavirus middle- $T$ antigen. I. Virol. 65: $170-179$.

Cobb, B.S., M.D. Schaller, T.-H. Leu, and J.T. Parsons. 1994. Stable association of $\mathrm{pp} 60^{\text {src }}$ and $\mathrm{pp} 59^{\text {fyn }}$ with the focal adhesion-associated protein tyrosine kinase, pp125 $5^{\mathrm{FAK}}$. Mol. Cell. Biol. 14: 147-155.

Cooper, J.A. and B. Howell. 1993. The when and how of src regulation. Cell 73: 1051-1054.

Courtneidge, S.A., R. Dhand, D. Pilat, G.M. Twamley, M.D. Waterfield, and M.F. Roussel. 1993. Activation of src family kinases by colony stimulating factor-1, and their association with its receptor. EMBO J. 12: 943-950.

Courtneidge, S.A. and A.E. Smith. 1984. The complex of polyoma virus middle-T antigen and pp $60^{\text {c-src }}$. EMBO I. 3: 585591.

da Silva, A.J. and C.E. Rudd. 1993. A 72-Kilodalton fyn-related polypeptide $\left(\mathrm{p} 72^{\mathrm{fyn}-\mathrm{R}}\right)$ binds to the antigen-receptor/CD3 (TcR/CD3) complex. J. Biol. Chem. 268: 16537-16543.

Djian, P., M. Phillips, K. Easley, E. Huang, M. Simon, R.H. Rice, and $H$. Green. 1993. The involucrin gene of the mouse and rat: Study of their shared repeats. Mol. Biol. Evol. 10: 11361149.

Dlugosz, A.A. and S.H. Yuspa. 1993. Coordinate changes in gene expression which mark the spinous to granular cell transition in epidermis are regulated by protein kinase C. I. Cell Biol. 120: 217-225.

Dotto, G.P., M.Z. Gilman, M. Maruyama, and R.A. Weinberg. 1986. c-myc and c-fos expression in differentiating mouse primary keratinocytes. EMBO I. 5: 2853-2857.

Downing, J.R. and A.B. Reynolds. 1992. PDGF, CSF-1, and EGF induce tyrosine phosphorylation of $\mathrm{p} 120$, a pp $60^{\text {src }}$ transformation-associated substrate. Oncogene 6: 607-613.

Druker, B.J., H.J. Mamon, and T.M. Roberts. 1989. Oncogenes, growth factors and signal transduction. New Engl. I. Med. 321: 1383-1391.

Ellis, C., M. Moran, F. McCormick, and T. Pawson. 1990. Phosphorylation of GAP and GAP-associated proteins by transforming and mitogenic tyrosine kinases. Nature 343: 377381 .

Filvaroff, E., D.F. Stern, and G.P. Dotto. 1990. Tyrosine phosphorylation is an early and specific event involved in primary keratinocyte differentiation. Mol. Cell. Biol. 10: 1164 1173.

Filvaroff, E., E. Calautti, F. Mc Cormick, and G.P. Dotto. 1992. Specific changes of Ras GTPase Activating Protein (GAP) and a GAP-associated p 62 protein during calcium-induced keratinocyte differentiation. Mol. Cell. Biol. 12: 5319-5328.

Filvaroff, E., E. Calautti, M. Reiss, and G.P. Dotto. 1994. Functional evidences for an extracellular calcium receptor mechanism triggering tyrosine kinase activation associated with mouse keratinocyte differentiation. I. Biol. Chem. 269: 21735-21740.

Gee, C.E., J. Griffin, L. Sastre, L.J. Miller, T.A. Springer, H.
Piwnica-Worms, and T.M. Roberts. 1986. Differentiation of myeloid cells is accompanied by increased levels of $\mathrm{pp} 60^{c-s r c}$ protein and kinase activity. Proc. Natl. Acad. Sci. 83: 51315135.

Glenney, J.R. Jr., L. Zokas, and M.P. Kamps. 1988. Monoclonal antibodies to phosphotyrosine. I. Immunol. Methods 109: 277-285.

Grant, S.G.N., T.J. O'Dell, K.A. Karl, P.K. Stein, P. Soriano, and E.R. Kandel. 1992. Impaired long-term potentiation, spatial learning, and hippocampal development in fyn mutant mice. Science 258: 1903-1910.

Hennings, H. and K.A. Holbrook. 1983. Calcium regulation of cell-cell contact and differentiation of epidermal cells in culture: An ultrastructural study. Exp. Cell Res. 143: 127-142.

Hennings, H., D. Michael, C. Cheng, P. Steinert, K. Holbrook, and S.H. Yuspa. 1980. Calcium regulation of growth and differentiation of mouse epidermal cells in culture. Cell 19: 245-254.

Hennings, H., K.A. Holbrook, and S.H. Yuspa. 1983. Factors influencing calcium-induced terminal differentiation in cultured mouse epidermal cells. J. Cell. Physiol. 116: 265-281.

Huang, M.-M., J.B. Bolen, J.W. Barnwell, S.J. Shattil, and J.S. Brugge. 1991. Membrane glycoprotein IV (CD36) is physically associated with the fyn, lyn, and yes protein-tyrosine kinases in human platelets. Proc. Natl. Acad. Sci. 88: 7844 7848.

Hurley, T.R., R. Hyman, and B.M. Sefton. 1993. Differential effects of expression of the CD45 tyrosine protein phosphatase on the tyrosine phosphorylation of the lck, fyn, and c-src tyrosine protein kinases. Mol. Cell. Biol. 13: 16511656.

Kamps, M.P. and B.M. Sefton. 1988. Identification of multiple novel polypeptide substrates of the $v$-src, $v$-yes, $v$-fps, $v$-ros, and $v-e r b-B$ oncogenic tyrosine protein kinases utilizing antisera against phosphotyrosine. Oncogene 2: 305-316.

1989. Acid and base hydrolysis of phosphoproteins bound to Immobilon facilitates the analysis of phosphoamino acids in gel-fractionated proteins. Anal. Biochem. 176: 22-27.

Kanner, S.B., A.B. Reynolds, R.R. Vines, and J.T. Parsons. 1990. Monoclonal antibodies to individual tyrosine-phosphorylated protein substrates of oncogene-encoded tyrosine kinases. Proc. Nat1. Acad. Sci. 87: 3328-3332.

Kypta, R.M., Y. Goldberg, E.T. Ulug, and S.A. Courtneidge. 1990. Association between the PDGF receptor and members of the src family of tyrosine kinases. Cell 62: 481-492.

Lee, E. and S.H. Yuspa. 1991. Changes in inositol phosphate metabolism are associated with terminal differentiation and neoplasia in mouse keratinocytes. Carcinogenesis 12: 16511658.

Lipsich, L., A.J. Lewis, and J.S. Brugge. 1983. Isolation of monoclonal antibodies that recognize the transforming proteins of avian sarcoma viruses $J$. Virol. 48: 352-360.

Luna, E.J. and A.L. Hitt. 1992. Cytoskeleton-plasma membrane interactions. Science 258: 955-963.

Luo, K. and B.M. Sefton. 1990. Analysis of the sites in p56 $6^{\text {lck }}$ whose phosphorylation is induced by tetradecanoyl phorbol acetate. Oncogene 5: 803-808.

Maa, M.-M., L.K. Wilson, J.S. Moyers, R.R. Vines, I.T. Parsons, and S.J. Parsons. 1992. Identification and characterization of a cytoskeleton-associated, epidermal growth factor sensitive pp60 ${ }^{\text {src }}$ substrate. Oncogene 7: 2429-2438.

Menon, G.K., S. Grayson, and P.M. Elias. 1985. Ionic calcium reservoirs in mammalian epidermis: Ultrastructural localization by ion-capture cytochemistry. I. Invest. Dermatol. 84: 508-512. 
Moscat, J., T.P. Fleming, C.J. Molloy, M. Lopez-Barahona, and S.A. Aaronson. 1989. The calcium signal for Balb/MK keratinocyte terminal differentiation induces sustained alterations in phosphoinositide metabolism without detectable protein kinase C activation. J. Biol. Chem. 264: 1122-11235.

Pazin, M.J. and L.T. Williams. 1992. Triggering signaling cascades by receptor tyrosine kinases. Trends in Biochem. Sci. 17: 374-378.

Reiss, M., L.R. Lipsey, and Z.L. Zhou. 1991. Extracellular calcium-dependent regulation of transmembrane calcium fluxes in murine keratinocytes. I. Cell. Physiol. 147: 281291.

Soriano, P., C. Montogomery, R. Geske, and A. Bradley. 1991. Targeted disruption of the $c$-src proto-oncogene leads to osteopetrosis in mice. Cell 64: 693-702.

Stein, P., H.M. Lee, S. Rich, and P. Soriano. 1992. pp59 ${ }^{f y n} \mathrm{mu}-$ tant mice display differential signaling in thymocytes and peripheral T cells. Cell 70: 741-750.

Stein, P.L., H. Vogel, and P. Soriano. 1994. Combined deficiencies of $s r c$, fyn, and yes tyrosine kinases in mutant mice. Genes \& Dev. 8: 1999-2007.

Sudol, M., H. Greulich, L. Newman, A. Sarkar, J. Sukegawa, and T. Yamamoto. 1993. A novel yes-related kinase, yrk, is expressed at elevated levels in neural and hematopoietic tissues. Oncogene 8: 823-831.

Thacer, S.M. and R.H. Rice. 1985. Keratinocyte-specific transglutaminase of cultured human epidermal cells: Relation to cross-linked envelope formation and terminal differentiation. Cell 40: 685-695.

Wong, G., O. Muller, R. Clark, L. Conroy, M.F. Moran, P. Polakis, and F. McCormick. 1992. Molecular cloning and nucleic acid binding properties of the GAP-associated tyrosine phosphoprotein p62. Cell 69: 551-558.

Wong, S., A.B. Reynolds, and J. Papkoff. 1992. Platelet activation leads to increased c-src kinase activity and association of c-src with an $85-\mathrm{kDa}$ tyrosine phosphoprotein. Oncogene 7: 2407-2415.

Wu, H., A.B. Reynolds, S.B. Kanner, R.R. Vines, and J.T. Parsons. 1991. Identification and characterization of a novel cytoskeleton-associated pp60 src substrate. Mol. Cell. Biol. 11: 5113-5124.

Wu, H. and J.T. Parsons. 1993. Cortactin, an 80/85 Kilodalton pp $60^{s r c}$ substrate, is a filamentous actin-binding protein enriched in the cell cortex. J. Cell Biol. 120: 1417-1426.

Yuspa, S.H. 1994. The pathogenesis of squamous cell cancer: Lessons learned from studies of skin carcinogenesis- Thirtythird G. H. A. Clowes Memorial Award Lecture. Cancer Res. 54: 1178-1189.

Yuspa, S.H., H.M. Kulesz-Martin, T. Ben, and H. Hennings. 1983. Transformation of epidermal cells in culture. I. Invest. Dermatol. 81: 162s-168s.

Yuspa, S.H., A.E. Kilkenny, P.M. Steinert, and D.R. Roop. 1989. Expression of murine epidermal differentiation markers is tightly regulated by restricted extracellular calcium concentrations in vitro. J. Cell. Biol. 109: 1207-1217.

Zhao, Y., H. Baker, S.I. Walaas, and M. Sudol. 1991. Localization of p62 $2^{c-y e s}$ protein in mammalian neural tissues. Oncogene 6: 1725-1733.

Zhao, Y., M. Sudol, H. Hanafusa, and I. Krueger. 1992. Increased tyrosine kinase activity of $c$-src during calcium-induced keratinocyte differentiation. Proc. Natl. Acad. Sci. 89: 82988302.

Zhao, Y., H. Uyttendaele, J.G. Krueger, M. Sudol, and H. Hanafusa. 1993. Inactivation of $c$-yes tyrosine kinase by elevation of intracellular calcium levels. Mol. Cell. Biol. 13: $7507-7514$. 


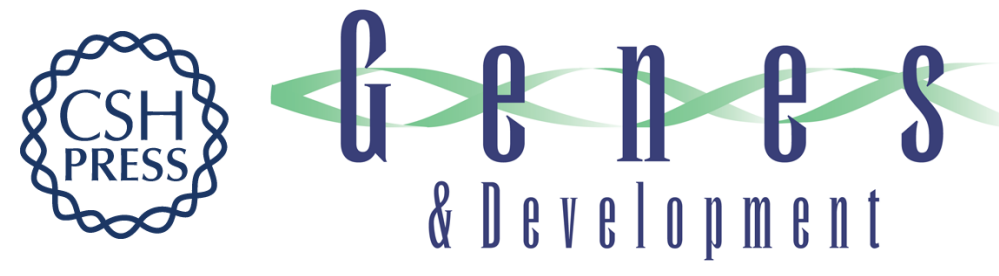

\section{fyn tyrosine kinase is involved in keratinocyte differentiation control.}

E Calautti, C Missero, P L Stein, et al.

Genes Dev. 1995, 9:

Access the most recent version at doi:10.1101/gad.9.18.2279

References This article cites 55 articles, 22 of which can be accessed free at:

http://genesdev.cshlp.org/content/9/18/2279.full.html\#ref-list-1

License

Email Alerting Receive free email alerts when new articles cite this article - sign up in the box at the top Service right corner of the article or click here.

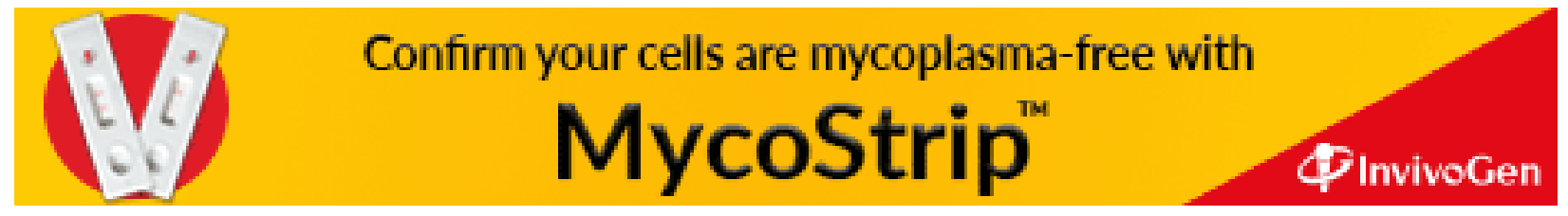

